\title{
Strength Loss of Basalt-Based Mineral Fibers after Thermal Desizing
}

\author{
Florian Boutenel*, Gilles Dusserre, Thierry Cutard
}

ICA (Institut Clément Ader), Université de Toulouse, CNRS, IMT Mines Albi, INSA, UPS, ISAE-SUPAERO Campus Jarlard, CT Cedex 09, Albi F-81013, France

Corresponding Author Email: florian.boutenel@mines-albi.fr

https://doi.org/10.18280/rcma.303-401

Received: 17 April 2020

Accepted: 5 May 2020

Keywords:
basalt fibers, desizing, heat treatment,
mechanical properties

\section{Keywords:}

mechanical properties

\begin{abstract}
This study investigates the effects of desizing by heat cleaning on tensile properties of basalt-based mineral fibers. Two heat treatments, which lead to a complete removal of the sizing layer, were considered: one at low temperature $\left(350^{\circ} \mathrm{C}\right)$ for a long time $(10 \mathrm{~h})$ and one at high temperature $\left(600^{\circ} \mathrm{C}\right)$ for a short time $(35 \mathrm{~min})$. Desizing greatly affects tensile strength. High temperature and short time treatment conditions lead to the most severe strength degradation (66\%). SEM micrographs reveal that failure originates from surface defects. Mechanisms responsible for strength loss were investigated by X-ray diffraction analyses, density measurements and differential thermal analyses. Strength degradation is ascribed to sizing layer removal and to thermally activated structural rearrangement of basalt.
\end{abstract}

\section{INTRODUCTION}

As natural material, basalt is a volcanic rock originated from solidified lava. Its chemical composition is similar to glass [1]: silica and alumina are the main constituents and this $\mathrm{SiO}_{2}$ $\mathrm{Al}_{2} \mathrm{O}_{3}$ system is completed by oxides such as $\mathrm{CaO}, \mathrm{Fe}_{2} \mathrm{O}_{3}$, $\mathrm{MgO}, \mathrm{K}_{2} \mathrm{O}, \mathrm{Na}_{2} \mathrm{O}$ and $\mathrm{TiO}_{2}$. The chemical composition may vary according to the geographical location of extraction sites, as well as from batch to batch. This is the reason of the recent development of mineral fibers based on natural basalt, whose composition is adjusted depending on the raw material. Similarly to glass fibers, continuous basalt fibers are produced by spinning method [1]. The basalt rocks are molten at $1,500^{\circ} \mathrm{C}-1,700^{\circ} \mathrm{C}$ and are then directly extruded through small nozzles to produce continuous filaments. However, the production of basalt fibers is less energy consuming than glass ones and needs no additives. Moreover, they possess relatively good mechanical, thermal and chemical properties compared to glass fibers [2]. Thus, basalt represents a relevant alternative to glass as fibrous reinforcement for composite materials. Basalt fibers are thus widely used with polymer, metallic or concrete matrices [3].

In order to protect the fibers over the weaving process or over any handling, a thin coating, called sizing, is applied on the fibers surface during manufacturing. This coating mainly comprises organic materials involving a film former, a coupling agent, a lubricant and sometimes other additives (such as anti-static agents, emulsifiers, chopping aids, wetting agents and antioxidants) [4]. However, the exact composition is often preserved by manufacturers as secret recipes [5]. Due to its presence on the fiber surface, sizing is a critical element in the properties of the fiber-matrix interfaces and thus in the design of composite materials. Nonetheless, if the sizing is not adapted to the matrix, its presence could negatively affect the interface properties, weakening the mechanical performances of the composite $[6,7]$. Furthermore, some studies [8, 9] have shown that fiber coatings, using relevant coupling agents and replacing the manufacturer sizing, could improve the interface properties and thus produce high performance composites. As a consequence, the sizing should be removed in some specific cases. This step is identified as the desizing and can be achieved by a chemical or heat treatment.

The effects of heat treatment on mechanical properties of basalt fibers have been investigated in several studies [10-15]. But, to the authors' knowledge, none deals with the effects of thermal desizing, and thus consider long time heat treatment. However, a reduction of tensile strength is commonly observed following heat treatment. Also, the mechanisms responsible for this degradation are not well understood and are still under discussion in the literature. This is due to the fact that the investigated fiber grades are different and possess dissimilar chemical compositions. Three main mechanisms have been proposed:

(1) Crystallization is the most frequently one mentioned in the literature [10-13]. Crystallization begins with the oxidation of the iron-rich phase. It leads to the formation of small crystallites of magnetite. They act as nucleation sites for the precipitation of a major phase which has a pyroxene structure [16]. Moreover, those crystallites represent heterogeneities in the fiber volume and are sources of defects, thus decreasing the tensile strength. Crystallization mechanisms are further discussed in Section 3.2.

(2) Bhat et al. [14] performed tensile tests at room temperature on single fibers and on single tows, previously heat treated between $250^{\circ} \mathrm{C}$ and $650^{\circ} \mathrm{C}$ for up to $2 \mathrm{~h}$. The aim of this study was to investigate the reduction of tensile strength following treatment of incineration of waste composite materials. Above $250^{\circ} \mathrm{C}$, the tensile strength rapidly decreases and is reduced by more than $65 \%$ at $450^{\circ} \mathrm{C}-600^{\circ} \mathrm{C}$. However, the Young's modulus is not affected by heat treatment, even at 
the maximum temperature. Thus, the authors attributed this strength loss to a thermally activated growth of surface flaws, probably resulting from a reaction process of the silicates of basalt with water molecules within the air.

(3) Sarasini et al. [15] measured, at room temperature, the mechanical properties of single fibers heat treated for $1 \mathrm{~h}$ up to $600^{\circ} \mathrm{C}$ in air and in argon. Regardless of the atmosphere, the tensile strength is reduced after heat treatment. In air, it reduces rapidly when increasing temperature up to $400^{\circ} \mathrm{C}$ to reach a quarter of its initial value at $600^{\circ} \mathrm{C}$. Nonetheless, in this study, the Young's modulus was found to increase with the treatment temperature. The strength loss is linked to decomposition of the organic sizing and primarily to structural anisotropy relaxation, involving both local structural rearrangement and defect reorientation. A densification phenomenon, for which the fiber density and the Young's modulus increase with the temperature, highlights this structural relaxation.

Thus, regarding the discussions in the literature, the effects of heat treatment on mechanical properties of basalt fibers are strongly linked to chemical composition and to treatment conditions (time and temperature).

The aim of the present work is to investigate the effects of desizing by heat treatment on the mechanical properties of commercial basalt-based natural fibers. The tensile properties of single fibers are measured after two heat treatments in air: the first one at low temperature $\left(350^{\circ} \mathrm{C}\right.$, representative of the maximum in-use temperature of polymer matrix composites [17]) and the second one at high temperature $\left(600^{\circ} \mathrm{C}\right.$, representative of the processing of metal matrix composites [18]). The treatment times are determined by isothermal thermogravimetric analysis in order to obtain a complete desizing of the fibers. The mechanisms responsible for the loss in strength, caused by the heat treatment, are investigated. The discussion is based on the results of X-ray diffraction analyses, density measurements and differential thermal analyses. For the first time, the degradation of the mechanical properties of basalt fibers following a heat treatment is determined in the specific case of desizing.

\section{MATERIAL AND METHODS}

\subsection{Raw material}

The commercial grade of continuous mineral fibers (Filava $^{\mathrm{TM}}$ - coated with the PVA based sizing referenced as IS65) considered in this study were provided by Isomatex S.A., Belgium. This grade is the result of an enrichment of the basalt with various mineral additives in order to improve the properties of the raw material. The components used in the batch aggregation and the fabrication process are part of Isomatex's expertise. The fibers were supplied as a roving of 100 Tex with a nominal fiber diameter of $11 \mu \mathrm{m}$. The

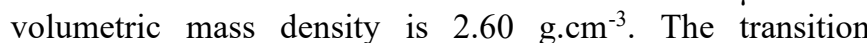
temperature and the softening point are given as equal to $730^{\circ} \mathrm{C}$ and to $940^{\circ} \mathrm{C}$, respectively [19]. The fibers were used as received from the manufacturer and after heat treatment.

Moreover, the density of the mineral fibers (before and after each heat treatment) was measured by helium pycnometry [20] using an AccuPyc 1340 pycnometer. The measurements were repeated three times on each sample. The mean value and the $95 \%$ confidence interval were calculated for each condition. The density of sized fibers is equal to $2.584 \mathrm{~g} . \mathrm{cm}^{-3}$ while it is
2.640 g. $\mathrm{cm}^{-3}$ for the desized fibers (heat treated at $350^{\circ} \mathrm{C}$ for $10 \mathrm{~h})$.

\subsection{Heat treatment}

In order to determine the treatment durations required to obtain a complete desizing of the fibers at the two considered temperatures $\left(350^{\circ} \mathrm{C}\right.$ and $\left.600^{\circ} \mathrm{C}\right)$, an analysis of the mass loss of the fibers under isothermal conditions was performed using a SetSys Evolution thermogravimetric analyzer (Setaram Instrumentation). The as-received fibers were initially placed in an alumina sample holder and heated at a rate of $10^{\circ} \mathrm{C} \cdot \mathrm{min}$ ${ }^{1}$ up to the maximum temperature $\mathrm{T}_{\max }\left(350^{\circ} \mathrm{C}\right.$ or $\left.600^{\circ} \mathrm{C}\right)$. Then, the samples were maintained at this temperature during $11 \mathrm{~h}$ (for $\mathrm{T}_{\max }=350^{\circ} \mathrm{C}$ ) or $1 \mathrm{~h}\left(\right.$ for $\mathrm{T}_{\max }=600^{\circ} \mathrm{C}$ ). All the analyses were performed in air. A typical example of the mass evolution during the analysis is given in Figure 1.

The mass loss is attributed to the desizing. Three main steps can be distinguished:

(1) From $t=0 \mathrm{~s}$ to $\mathrm{t}=1125 \mathrm{~s}$, the mass loss is low because the temperature is high enough to remove the residual water of the sizing but not the organic materials.

(2) From $t=1125 \mathrm{~s}$ to $\mathrm{t}=3000 \mathrm{~s}$, the main part of the sizing is removed.

(3) From $t=3000 \mathrm{~s}$ to $\mathrm{t}=5500 \mathrm{~s}$, the mass decrease continues at a very slow rate. Indeed, it corresponds to the removal of the residual organic layers.

The mass loss observed in this case is equal to $1.88 \%$. Moreover, by assuming that the fibers have a mean diameter of $12 \mu \mathrm{m}$ (Table 1), a density of $2.584{\mathrm{~g} . \mathrm{cm}^{-3}}^{-3}$ if sized and 2.640 g. $\mathrm{cm}^{-3}$ if desized, the thickness and the density of the sizing layer are evaluated at $0.12 \mu \mathrm{m}$ and $1.22{\mathrm{~g} . \mathrm{cm}^{-3}}^{-3}$, respectively. As reported by Thomason [5], the coating thickness is usually in the wide range from $1 \mathrm{~nm}$ to $1 \mathrm{~mm}$. The thickness evaluated here is included in this range. Further, the density value of sizing is consistent with the one of PVA $\left(1.19-1.31 \mathrm{~g} . \mathrm{cm}^{-3}\right)$.

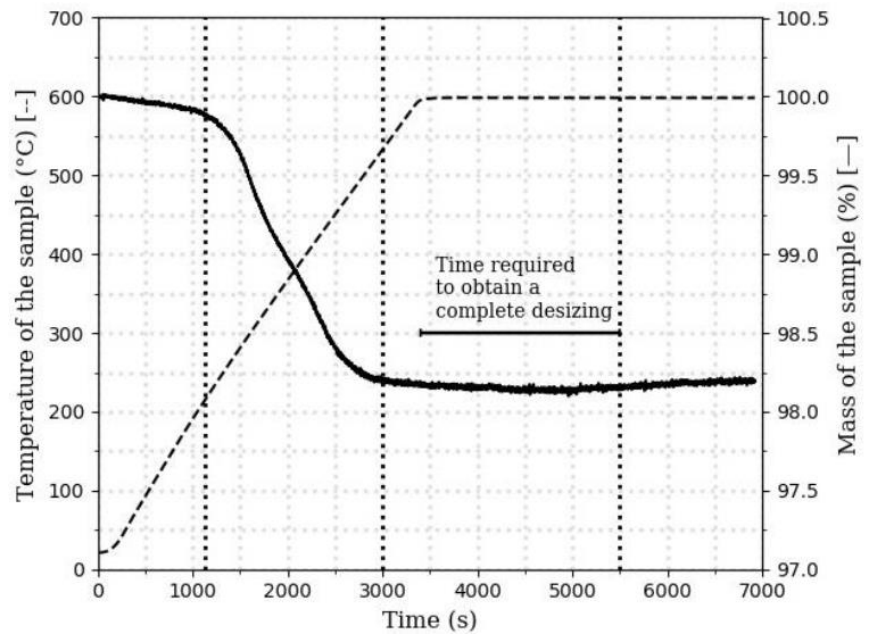

Figure 1. Mass variation of basalt fibers measured by TGA. The as-received fibers were heated at a rate of $10^{\circ} \mathrm{C} \cdot \mathrm{min}^{-1}$ up to $600^{\circ} \mathrm{C}$ and were maintained at this temperature for $1 \mathrm{~h}$ in air

So, the treatment time is chosen in order to reach the minimum mass which makes sure of a complete desizing of the fibers. For $\mathrm{T}_{\max }=350^{\circ} \mathrm{C}$, the treatment time is thus $10 \mathrm{~h}$ while it is $35 \mathrm{~min}$ for $\mathrm{T}_{\max }=600^{\circ} \mathrm{C}$.

Consecutive to those analyses, the heat treatments of 
desizing were performed on as-received fiber bundles using a furnace with programmable temperature controller (model $\mathrm{N} 11 / \mathrm{H}$ with programmer C290, Nabertherm GmbH). To be consistent with the thermogravimetric analyses, the bundles were heated from room temperature to $350^{\circ} \mathrm{C}$ or $600^{\circ} \mathrm{C}$ at a rate of $10{ }^{\circ} \mathrm{C} \cdot \mathrm{min}^{-1}$. Then, the fibers were maintained at this temperature during the treatment duration previously determined $\left(10 \mathrm{~h}\right.$ for $\mathrm{T}_{\max }=350^{\circ} \mathrm{C}$ and $35 \mathrm{~min}$ for $\mathrm{T}_{\max }=$ $600^{\circ} \mathrm{C}$ ). The heat treatments were performed in air and no load was applied during the processing. Finally, the bundles were removed from the furnace and cooled in air at room temperature before testing.

\subsection{Single fiber tensile tests}

The mechanical properties of basalt fibers were investigated by tensile tests performed on single filaments. The tests were achieved by adapting the ISO standard 11566:1996 [21] to basalt fibers. Individual fibers were carefully separated by hand from the fiber bundles (untreated and heat treated). Each single fiber was fixed on a specific cardboard. A rectangular window was cut in the center of it. The length of the rectangular window is $25 \mathrm{~mm}$, thereby defining the gauge length. The fiber was glued onto the cardboard at both sides of the window with an instant adhesive (Loctite ${ }^{\mathrm{TM}}$ 406). The diameter of each fiber was calculated as the average of five measurements carried out at different positions along the gauge length of the fiber, using a scanning electron microscope Hitachi TM3030Plus. Afterwards, the tensile tests were performed at room temperature on an Instron 5942 testing machine equipped with a $5 \mathrm{~N}$ load cell. Successively, each specimen was clamped to the testing machine, the cardboard was cut and the filament was stretched. The test speed was fixed at a crosshead displacement rate of $1 \mathrm{~mm} . \mathrm{min}^{-}$

1 . For each state investigated in this study (untreated, heat treated at $350^{\circ} \mathrm{C}$ and heat treated at $600^{\circ} \mathrm{C}$ ), 40 specimens were tested. The tensile strength, the elastic modulus and the elongation at break were measured according to ISO standard 11566:1996 and, for each condition, the mean values and the $95 \%$ confidence intervals were also calculated. Furthermore, the system compliance was determined by considering results obtained on untreated specimens, by taking into account variations in the fiber diameter, as described in the paper [22]. Three-gauge lengths were considered $(5 \mathrm{~mm}, 25 \mathrm{~mm}$ and 45 $\mathrm{mm})$ and for each one, ten specimens were tested. The system compliance was evaluated at $0.4326 \mathrm{~mm} . \mathrm{N}^{-1}$.

The statistics of fracture in a brittle material such as a ceramic fiber can be described by the Weibull distribution. This distribution is based on the "weakest link theory". It means that the fracture is controlled by the weakest defect existing in the material. A two-parameter Weibull distribution can be expressed as:

$$
P_{f}=1-\exp \left(-\left(\frac{\sigma}{\sigma_{0}}\right)^{\mathrm{m}}\right)
$$

where, $\mathrm{P}_{f}$ is the probability of failure and $\sigma$ the tensile strength; $\mathrm{m}$ the Weibull modulus and $\sigma_{0}$ a scale parameter was determined by using the maximum likelihood method, as described in the paper [23]. For each investigated state, the 40 measurements were considered for the Weibull analysis. Furthermore, the Anderson-Darling test [24] was used to assess the fit of the Weibull distribution to the experimental data. This test is based upon the area of discrepancy between the empirical and the theoretical distribution functions. The
Anderson-Darling statistics $A_{n}^{2}$ is expressed as:

$$
\begin{gathered}
A_{n}^{2}=-n-\frac{1}{n} \sum_{i=1}^{n}(2 i-1) \ln (P i)+(2 n+1-2 i) \\
\ln (1-P i)
\end{gathered}
$$

where, $\mathrm{n}$ is the number of tested fibers and $P i$ the probability of failure associated to the ith ranked value of tensile strength. As an approximated rule [25], only values of $A_{n}^{2} \leq 0.5$ are likely to have meaningful significance.

\subsection{Scanning electron microscopy (SEM)}

The surface morphologies of the basalt fibers, before and after desizing, were observed using a scanning electron microscope Nova NanoSEMTM 450 operated at $15 \mathrm{keV}$. The fracture surfaces of the fibers were also examined after tensile testing.

\subsection{X-ray diffraction (XRD)}

X-ray diffraction analyses were performed on the asreceived and heat-treated fibers. XRD patterns were collected at room temperature using a Philips X'Pert diffractometer equipped with a $\mathrm{X}^{\prime}$ Celerator PW 3373 detector $\left(\mathrm{Cu}-\mathrm{K}_{\alpha 1}=\right.$ $1.54060 \AA-\mathrm{K}_{\alpha 2}=1.54443 \AA$ ) in the range of $2 \theta=10^{\circ}-50^{\circ}$ with a scan step of $2 \theta=0.067^{\circ}$ and a scan rate of $2.55^{\circ} \cdot \mathrm{min}^{-1}$.

\subsection{Differential thermal analysis (DTA)}

Differential thermal analyses were performed on each fiber state using a SetSys Evolution thermal analyzer (Setaram Instrumentation). Each sample was placed in an alumina sample holder and heated at a rate of $30{ }^{\circ} \mathrm{C} \cdot \mathrm{min}^{-1}$ to a maximum temperature of $1050^{\circ} \mathrm{C}$ in air. For each investigated state, the experiment was repeated three times. Moreover, the fictive temperature of basalt fibers was evaluated for each sample and the mean value was calculated for each condition. The concept of fictive temperature was defined by Tool [26]. A vitreous system in a given non-equilibrium glass state could be described in terms of an equivalent equilibrium liquid state at a different temperature. The fictive temperature is the temperature of this equivalent liquid state and could be calculated thanks to the Narayanaswamy's equation [27].

\section{RESULTS AND DISCUSSION}

\subsection{Effect of desizing on mechanical properties of basalt fibers}

As well as the diameters measurements, the tensile properties measured on untreated and treated fibers are reported in Table 1.

First, some insignificant differences of diameter can be observed between the three states. The parameters of the melt spinning process determine the diameter of the basalt fiber.

Bauer et al. [28] have observed diameter variation for fibers of a single section of the roving (up to $16 \%$ in some cases) and in the lengthwise direction of the fiber (between $1.0 \%$ and $1.5 \%$ ). In consequence, the scatter reported in this study can be attributed to the fluctuation of the process parameters. However, in order to correctly evaluate the mechanical properties of fibers, those scatters of diameters measurements should be taken into account. 
The mechanical properties were determined by single fiber tensile testing. No fiber bundle testing was achieved because, in this case, friction between fibers (strongly linked to the sizing which acts as lubricant) has to be taken into account and may interfere in the interpretation of the results. For each single tested fiber, the stress-strain curve (not represented here) shows an elastic linear behavior without any plastic deformation until failure. This evolution is characteristic of a brittle behavior. Thus, the brittle behavior of basalt fibers is not modified by the desizing.

Further, a study of the fracture surfaces was performed on fibers with and without heat treatments. For each state, Figure 2 shows a representative micrograph of a fracture surface.

In all cases, the morphology corresponds to the one reported for a brittle fiber. Indeed, three regions can be distinguished on each micrograph: the mirror (related to the crack source), the mist and the hackle (associated to the rupture). As indicated by an arrow on Figure 2, the failure origin is located on the fiber surface. Thus, it can be considered that the failure has a unique source and is governed by surface defects. Also, this shows that the failure mode is not changed by heat treatment.

However, a significant strength loss is observed between untreated and heat treated fibers (Table 1). Furthermore, this strength loss is more severe when increasing the heat treatment temperature. Compared to the as-received state, the tensile strength is reduced of $34 \%$ after a heat treatment at $350^{\circ} \mathrm{C}$ for $10 \mathrm{~h}$, while the reduction reaches $66 \%$ after a heat treatment at $600^{\circ} \mathrm{C}$ for $35 \mathrm{~min}$. Moreover, after this heat treatment at $600^{\circ} \mathrm{C}$, a significant increase of the Young's modulus is observed. The mechanisms related to those observations are discussed in Section 3.2. Nonetheless, a comparison with the works of Sarasini et al. [15] can be accomplished here. In fact, with a similar initial tensile strength, Sarasini et al. observed a strength loss of $75 \%$ after a treatment at $600^{\circ} \mathrm{C}$ for $1 \mathrm{~h}$ while, in the present study, for the same temperature, a loss of $66 \%$ is already observed after only $35 \mathrm{~min}$. Even if the fibers grades investigated in both studies are different, it could be assumed that the kinetics related to the strength loss is fast during the first moments of the treatment.

The results of Weibull analyses are reported in Table 2.

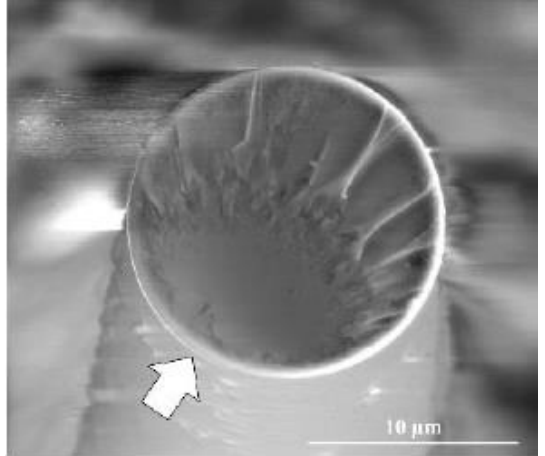

(a) As - received

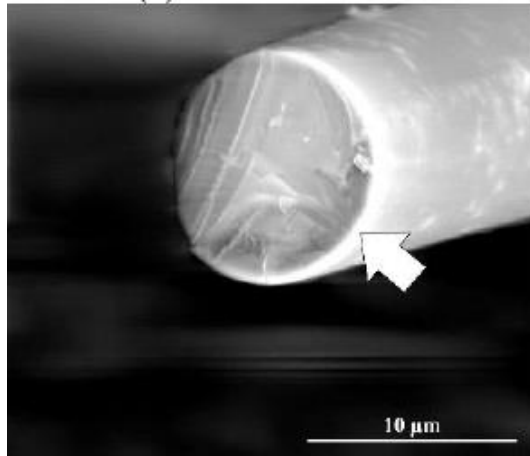

(b) Heat treated at $350^{\circ} \mathrm{C}$ for $10 \mathrm{~h}$

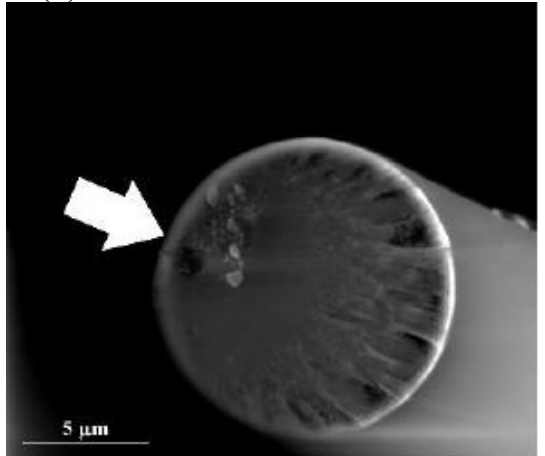

(c) Heat treated at $600^{\circ} \mathrm{C}$ for $35 \mathrm{~min}$

Figure 2. SEM micrographs of the fracture surfaces of basalt fibers - before and after desizing. The arrows indicate the location of the failure origin.

Table 1. Diameters and tensile properties of basalt fibers - before and after desizing

\begin{tabular}{cccc}
\hline & As-received & Heat treated at $\mathbf{3 5 0}{ }^{\circ} \mathbf{C}$ for $\mathbf{~ 1 0 ~} \mathbf{~}$ & Heat treated at $\mathbf{6 0 0}^{\circ} \mathbf{C}$ for 35 min \\
\hline Diameter $(\boldsymbol{\mu m})$ & $11.65 \pm 0.62$ & $11.89 \pm 0.44$ & $12.65 \pm 0.49$ \\
Tensile strength (MPa) & $2,126 \pm 181$ & $1,403 \pm 110$ & $718 \pm 45$ \\
Young's modulus (GPa) & $93 \pm 6$ & $94 \pm 3$ & $100 \pm 5$ \\
Elongation at break (\%) & $2.35 \pm 0.23$ & $1.50 \pm 0.12$ & $0.73 \pm 0.06$ \\
\hline
\end{tabular}

Table 2. Weibull parameters and Anderson-Darling statistics of basalt fibers - before and after desizing

\begin{tabular}{cccc}
\hline & As-received & Heat treated at 350 ${ }^{\circ} \mathbf{C}$ for $10 ~ h$ & Heat treated at 600 ${ }^{\circ} \mathbf{C ~ f o r ~ 3 5 ~} \mathbf{m i n}$ \\
\hline Weibull modulus $\mathbf{~ S ~ S c a l e ~}$ & 3.99 & 4.32 & 5.91 \\
parameter $\boldsymbol{\sigma}_{\mathbf{0}}(\mathbf{M P a})$ & 2,331 & 1,535 & 774 \\
Anderson -Darling statistics $\boldsymbol{A}_{\boldsymbol{n}}^{2}$ & 0.42 & 0.50 & 0.45 \\
\hline
\end{tabular}

The Anderson-Darling test confirms that the experimental data are well represented by a two-parameter Weibull distribution (Figure 3).

The values of the Weibull modulus and of the scale factor of untreated fibers are close to those reported in the literature for basalt fibers [29]. The variations of the scale parameter are analogous to those previously noticed for tensile strength. The as-received fibers and those heat treated at $350^{\circ} \mathrm{C}$ for $10 \mathrm{~h}$ have an almost similar Weibull modulus, while it is significantly higher for the fibers heat treated at $600^{\circ} \mathrm{C}$ for $35 \mathrm{~min}$. By using a two-parameter Weibull distribution, the failure of fibers is supposed to be controlled by a single type of flaws population. In addition, the Weibull modulus represents the scatter in the fracture strength [30]. A higher modulus corresponds to a 
lower dispersion of the fracture strength. As a consequence, the heat treatment at $600^{\circ} \mathrm{C}$ leads to a homogenization of flaws on fibers surface.

\subsection{Discussion on strength loss mechanisms}

The mechanisms responsible for the strength loss were investigated in several ways. Nonetheless, two features should be discussed, and will be analyzed in a two-step discussion. Firstly, the strength loss between untreated and heat treated fibers must be explained. That means that the desizing involves a degradation of mechanical properties. Secondly, the fact that the heat treatment at $600^{\circ} \mathrm{C}$ for $35 \mathrm{~min}$ is more damaging for fibers than the one at $350^{\circ} \mathrm{C}$ for $10 \mathrm{~h}$ should be considered.

As reported previously (see Section 3.1), basalt fibers have a brittle behavior and the failure initiation occurs near surface flaws. The desizing does not affect this behavior excepting the fact that the tensile strength is reduced. In other words, heat treatment promotes the fiber failure. In order to highlight the mechanisms specific to the desizing regardless of heat treatment conditions, the comparison between the as-received fibers and those heat treated at $350^{\circ} \mathrm{C}$ for $10 \mathrm{~h}$ should be considered. Indeed, the differences observed here cannot be attributed to structural changes. Various evidences show that the fibers possess the same structure in both cases. First, density measurements (Figure 4) were performed.

The density of the as-received fibers is equal to $2.584 \mathrm{g.cm}$ ${ }^{3}$ while it is 2.640 g. $\mathrm{cm}^{-3}$ for the fibers heat treated at $350^{\circ} \mathrm{C}$. This increase in density is attributed to desizing. In fact, the sizing layer disappears and the density of this organic layer is lower than the one of the basalts. Then, the Young's modulus is quite similar in both states (Table 1). The small discrepancy observed here is attributed to the removal of the sizing layer. Indeed, by assuming that the Young's modulus of the fibers (without sizing) is equal to $94 \mathrm{GPa}$ and the PVA-based sizing have a thickness of $0.12 \mu \mathrm{m}$ and a Young's modulus of $1.8 \mathrm{GPa}$, the Young's modulus of the sized fibers is evaluated at $90 \mathrm{GPa}$, which is consistent with the value of the as-received fibers. Moreover, X-ray diffraction analyses were performed (Figure $5)$.

The as-received fibers present a glass-like structure. This amorphous state results from the quick quench of the melt during the manufacturing. This structure is also found on the fibers heat treated at $350^{\circ} \mathrm{C}$. Finally, the fictive temperature of basalt fibers was evaluated using differential thermal analyses. Results are reported in Table 3.

No significant difference is observed between the asreceived fibers and those heat treated at $350^{\circ} \mathrm{C}$. As a consequence, according to these experimental results, it seems that the fiber structure is not significantly modified. The strength loss between the as-received fibers and those heat treated at $350^{\circ} \mathrm{C}$ is thus ascribed to the removal of the sizing layer. In fact, the sizing acts as a "protective" agent on surface flaws [31]. Figure 6 compares the surface of basalt fibers before and after desizing.

On the as-received fibers, the sizing layer is observable. Its non-uniformity is due to sizing process and to the fact that, before observation, the fibers were separated by hand from fibers bundles. After heat treatments, the fiber surface is clean and the flaws are revealed. The arrows represented in Figure 6(b) show examples of such surface flaws. The application of the sizing layer permits to fill the surface flaws by increasing the radius of curvature at the defect tip $[31,32]$ and "delays" the crack growth leading to the fiber failure. Without "protective" layer, flaws are more critical. As a consequence, the scale factor of the Weibull analysis decreases. But the flaws population is still the same and thus the Weibull modulus is similar between the as-received fibers and those heat-treated at $350^{\circ} \mathrm{C}$ (Table 2).

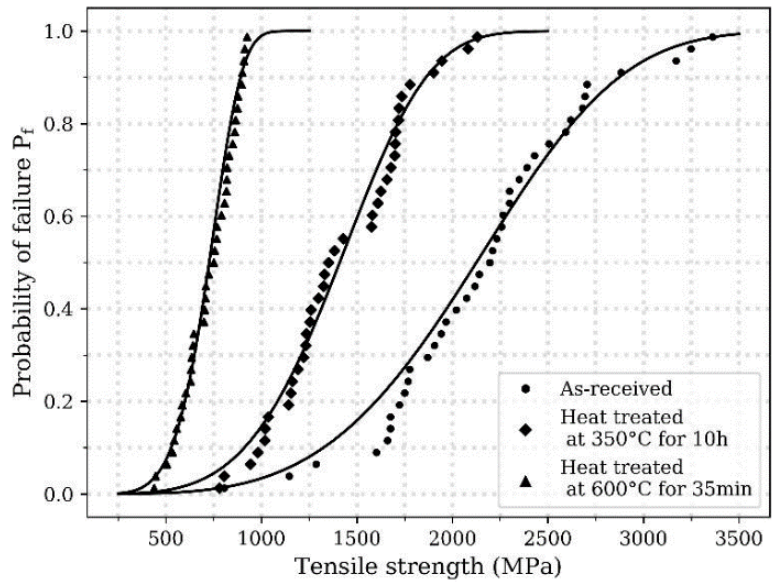

Figure 3. Weibull distribution of basalt fibers - before and after desizing. For each condition, the experimental data are represented by markers and the two-parameter Weibull distribution by a continuous line.

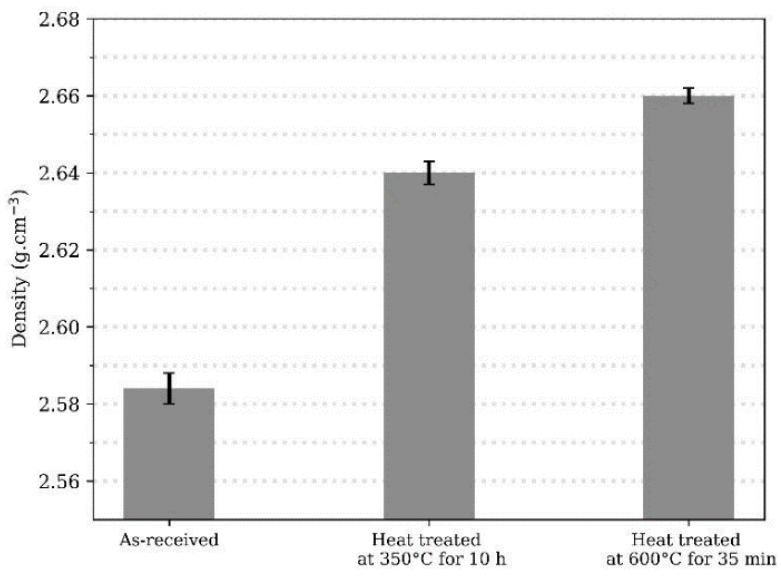

Figure 4. Density measurements of basalt fibers - before and after desizing

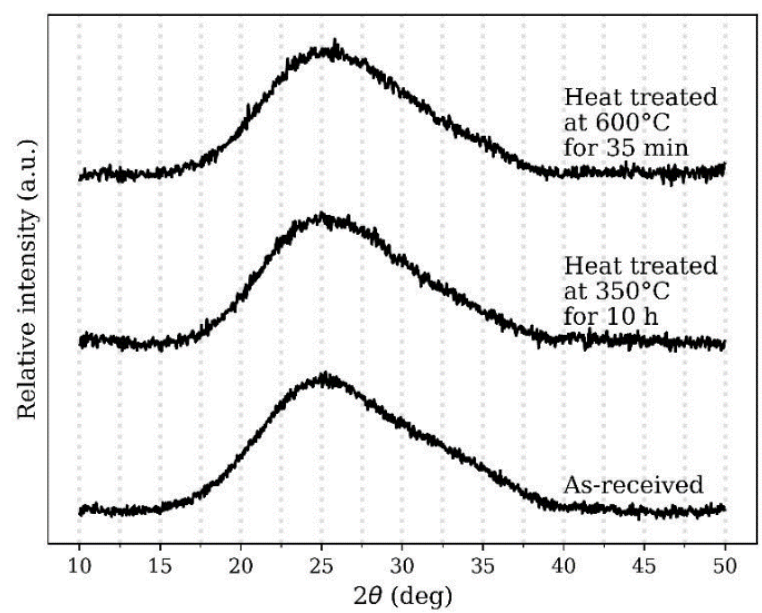

Figure 5. X-ray diffraction patterns of basalt fibers - before and after desizing 
Table 3. Fictive temperatures of basalt fibers determined by differential thermal analysis - before and after desizing

\begin{tabular}{lccc}
\hline & As-received & Heat treated at 350 ${ }^{\circ} \mathbf{C}$ for $\mathbf{~ 1 0 ~} \mathbf{~ h}$ & Heat treated at $600{ }^{\circ} \mathbf{C}$ for 35 min \\
\hline Fictive temperature $\left({ }^{\circ} \mathbf{C}\right)$ & $747 \pm 8$ & $742 \pm 4$ & $747 \pm 8$ \\
\hline
\end{tabular}

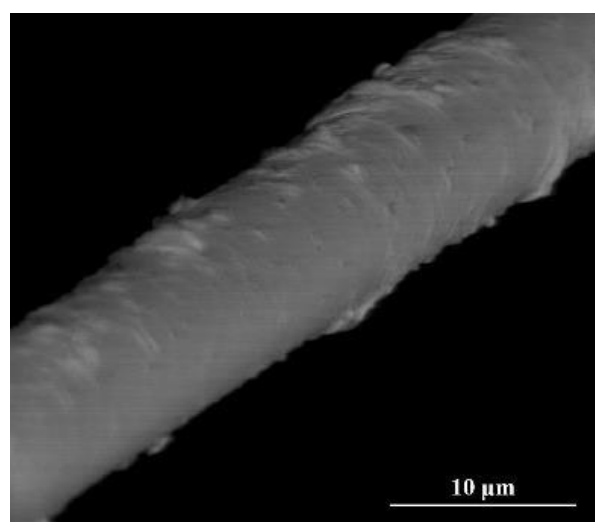

(a) As-received

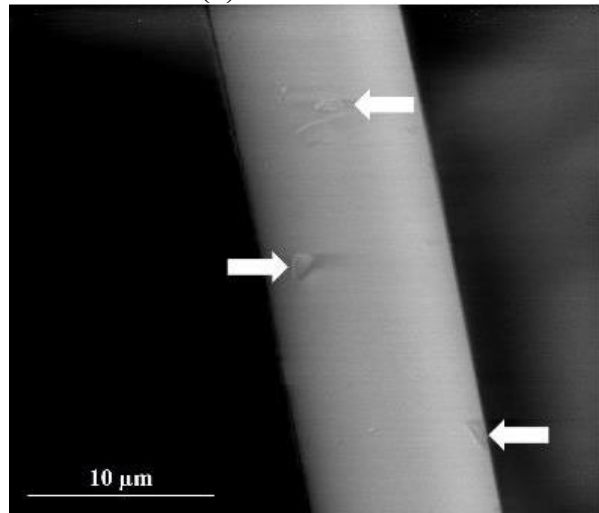

(b) After heat treatment at $350^{\circ} \mathrm{C}$ for $10 \mathrm{~h}$

Figure 6. SEM micrographs of the surface of basalt fibers before and after desizing. The arrows show the flaws on the fiber surface.

However, the strength loss between fibers heat treated at $350^{\circ} \mathrm{C}$ for $10 \mathrm{~h}$ and those heat treated at $600^{\circ} \mathrm{C}$ for $35 \mathrm{~min}$ involves the existence of another mechanism which is activated due to heat treatment conditions and occurs at the same time that the desizing. In other words, treating at $600{ }^{\circ} \mathrm{C}$, even during a short time, affects the internal structure of basalt fibers. Crystallization is the main factor which determines the thermal stability of basalt fibers [3]. Makhova [33], Gutnikov et al. [34] and Manylov et al. [16] have studied the crystallization behavior of basalt fibers. In particular, it begins with the oxidation of ferrous cations and the formation of a first crystal phase with spinel structure (magnetite) which is located on the fiber surface. In this study, the treatment temperature of $600^{\circ} \mathrm{C}$ could lead to this oxidation because the transition of $\mathrm{Fe}^{2+}$ into $\mathrm{Fe}^{3+}$ begins at $500^{\circ} \mathrm{C}-600^{\circ} \mathrm{C}$ and ends at $800^{\circ} \mathrm{C}-1,000^{\circ} \mathrm{C}$. In order to verify the presence of a crystalline layer at the fibers surface, X-ray diffraction analyses were performed (Figure 5). The structure observed for fibers heat treated at $600^{\circ} \mathrm{C}$ for $35 \mathrm{~min}$ is the same as the one observed for the other states. Moreover, no diffraction peaks were observed. Thus, the strength loss cannot be attributed to crystallization.

On the other hand, the assumption of a structural rearrangement [15] could be argued. In fact, following the quick quench of the melt during the manufacturing, the amorphous and non-equilibrium structure of the basalt tends to return to an equilibrium state with increasing the temperature. Even if the X-ray diffraction analyses (Figure 5) and fictive temperature measurements (Table 3) show no significant differences between the three states, some evidences seem to confirm the existence of this structural rearrangement. First, the density of fibers heat treated at $600^{\circ} \mathrm{C}$ is significantly greater than the one of fibers heat treated at $350^{\circ} \mathrm{C}$ (Figure 4). This increase can no longer be attributed to the removal of the sizing layer. But it could be interpreted as an evidence of the existence of the structural rearrangement. Moreover, the evolution of the elastic modulus is another one (Table 1). In fact, it is greater for the fibers heat treated at $600^{\circ} \mathrm{C}$ than for those heat treated at $350^{\circ} \mathrm{C}$. Those two increases (in density and in Young's modulus) are related to a densification phenomenon which could be interpreted as a consequence of the structural rearrangement.

This rearrangement could explain the results observed in this study. Following melting, the fibers are quenched, which induces residual compressive stresses at the fibers surface and forces the fibers core to vitrify with a specific volume superior to the one of the equilibrium states. The structural rearrangement would decrease those residual stresses and would make the flaws more critical. Thus, the tensile strength and the scale factor of the Weibull analysis decrease. Also, the structural rearrangement, which promotes a return to equilibrium, tends to decrease the specific volume of the fibers core. Thus, the density and the Young's modulus increase. If the quenching is not uniform, the residual compressive stresses are not uniform too along the fibers. It means that the dispersion of the fracture strength is high before relaxation. It is represented by a low value of Weibull modulus. The structural rearrangement would make then this dispersion more homogeneous. Thus, the Weibull modulus is superior for fibers heat treated at $600^{\circ} \mathrm{C}$ than for others.

\section{CONCLUSION}

The effects of desizing by heat treatment on mechanical properties of basalt fibers were investigated. Thanks to thermogravimetric analyses, two heat treatments were considered: one at low temperature $\left(350^{\circ} \mathrm{C}\right)$ for a long time $(10$ h) and one at high temperature $\left(600^{\circ} \mathrm{C}\right)$ for a short time $(35$ $\mathrm{min})$. Both lead to a complete removal of the sizing layer.

Single fiber tensile testing outcomes indicate that the tensile strength of basalt fibers is reduced due to desizing: by $34 \%$ for the first treatment and by $66 \%$ for the second one. It means that the heat treatment conditions have an influence on the degradation. Furthermore, basalt fibers possess a brittle behavior and SEM micrographs reveal that the failure is originated from the surface flaws. Also, heat treatments accelerate the failure without changing its nature.

Consequently, several experimental investigations were performed in order to determine the mechanisms responsible for the strength loss. First, the removal of the sizing layer reveals the defects at the fiber surface, thus promoting the crack growth which leads to the failure. Then, if the treatment conditions are too severe, the strength loss could also be ascribed to a rearrangement of the basalt structure. Fiber density and Young's modulus increase too. 


\section{ACKNOWLEDGMENT}

The authors would like to sincerely thank Isomatex S.A. for providing the mineral fibers considered in this study. This research received a grant from the Occitanie region and fundings from Institut Carnot M.I.N.E.S (ANR).

\section{REFERENCES}

[1] Deák, T., Czigány, T. (2009). Chemical composition and mechanical properties of basalt and glass fibers: A comparison. Textile Research Journal, 79(7): 645-651. https://doi.org/10.1177/0040517508095597

[2] Dhand, V., Mittal, G., Rhee, K.Y., Park, S.J., Hui, D. (2015). A short review on basalt fiber reinforced polymer composites. Composites Part B: Engineering, 73: 166180. https://doi.org/10.1016/j.compositesb.2014.12.011

[3] Fiore, V., Scalici, T., Di Bella, G.D., Valenza, A. (2015). A review on basalt fibre and its composites. Composites Part B: Engineering, 74: 74-94. https://doi.org/10.1016/j.compositesb.2014.12.034

[4] Thomason, J.L., Adzima, L.J. (2001). Sizing up the interphase: An insider's guide to the science of sizing. Composites Part A: Applied Science and Manufacturing, 32(3-4): 313-321. https://doi.org/10.1016/S1359$835 \mathrm{X}(00) 00124-\mathrm{X}$

[5] Thomason, J. (2012). Glass fibre sizings: A review of the scientific literature. Create Space Independent Publishing Platform.

[6] Cheng, T.H., Zhang, J., Yumitori, S., Jones, F.R., Anderson, C.W. (1994). Sizing resin structure and interphase formation in carbon fibre composites. Composites, 25(7): 661-670. https://doi.org/10.1016/0010-4361(94)90199-6

[7] Mayer, C., Neitzel, M. (1997). Influence of the sizing interphase on the static and dynamic behavior of advanced thermoplastic composites. In: Proc. ICCM-11 Gold Coast Aust., 681-690.

[8] Deák, T., Czigány, T., Tamás, P., Németh, C. (2010). Enhancement of interfacial properties of basalt fiber reinforced nylon 6 matrix composites with silane coupling agents. Express Polymer Letters, 4(10): 590598. https://doi.org/10.3144/expresspolymlett.2010.74

[9] Arslan, C., Dogan, M. (2018). The effects of silane coupling agents on the mechanical properties of basalt fiber reinforced poly (butylene terephthalate) composites. Composites Part B: Engineering, 146: 145-154. https://doi.org/10.1016/j.compositesb.2018.04.023

[10] Militký, J., Kovačič, V., Rubnerova, J. (2002). Influence of thermal treatment on tensile failure of basalt fibers. Engineering Fracture Mechanics, 69(9): 1025-1033. https://doi.org/10.1016/S0013-7944(01)00119-9

[11] Černý, M., Glogar, P., Goliáš, V., Hruška, J., Jakeš, P., Sucharda, Z., Vávrová, I. (2007). Comparison of mechanical properties and structural changes of continuous basalt and glass fibres at elevated temperatures. Ceramics-Silikáty, 51(2): 82-88.

[12] Ying, S., Zhou, X. (2013). Chemical and thermal resistance of basalt fiber in inclement environments. Journal of Wuhan University of Technology-Mater. Sci. Ed., 28(3): 560-565. https://doi.org/10.1007/s11595013-0731-4

[13] Sabet, S.M.M., Akhlaghi, F., Eslami-Farsani, R. (2015).
The effect of thermal treatment on tensile properties of basalt fibers. J. Ceram. Sci. Tech., 6: 245-248. https://doi.org/10.4416/JCST2014-00053

[14] Bhat, T., Fortomaris, D., Kandare, E., Mouritz, A.P. (2018). Properties of thermally recycled basalt fibres and basalt fibre composites. Journal of Materials Science, 53(3): 1933-1944. https://doi.org/10.1007/s10853-0171672-7

[15] Sarasini, F., Tirillò, J., Seghini, M.C. (2018). Influence of thermal conditioning on tensile behaviour of single basalt fibres. Composites Part B: Engineering, 132: 7786. https://doi.org/10.1016/j.compositesb.2017.08.014

[16] Manylov, M.S., Gutnikov, S.I., Pokholok, K.V., Lazoryak, B.I., Lipatov, Y.V. (2013). Crystallization mechanism of basalt glass fibers in air. Mendeleev Communications, 23(6): 361-363. https://doi.org/10.1016/j.mencom.2013.11.021

[17] Ramirez, M.L., Walters, R., Lyon, R.E., Savitski, E.P. (2002). Thermal decomposition of cyanate ester resins. Polymer Degradation and Stability, 78(1): 73-82. https://doi.org/10.1016/S0141-3910(02)00121-0

[18] Akhlaghi, F., Eslami-Farsani, R., Sabet, S.M.M. (2013). Synthesis and characteristics of continuous basalt fiber reinforced aluminum matrix composites. Journal of Composite Materials, 47(27): 3379-3388. https://doi.org/10.1177\%2F0021998312465765

[19] Product Information and Technical Data Sheet. (2018). $\begin{array}{lll}\text { Isomatex } & \text { S.A. }\end{array}$ https://www.isomatex.com/fr/page/direct-rovinglink.html.

[20] Rude, T.J., Strait Jr, L.H., Ruhala, L.A. (2000). Measurement of fiber density by helium pycnometry. Journal of Composite Materials, 34(22): 1948-1958. https://doi.org/10.1106/NUYP-PARA-RA5R-7NUE

[21] ISO 11566. (1996). Carbon fibre - Determination of the tensile properties of single-filament specimens. International Organization for Standardization.

[22] Li, C.T., Langley, N.R. (1985). Improvement in fiber testing of high-modulus single-filament materials. Journal of the American Ceramic Society, 68(8): 202204. 2916.1985.tb10183.x

[23] ASTM C1236-13. (2018). Standard Practice for Reporting Uniaxial Strength Data and Estimating Weibull Distribution Parameters for Advanced Ceramics. ASTM International. https://doi.org/10.1520/C123913R18

[24] Anderson, T.W., Darling, D.A. (1952). Asymptotic theory of certain "goodness of fit" criteria based on stochastic processes. The Annals of Mathematical Statistics, 23: 193-212. https://doi.org/10.1214/aoms/1177729437

[25] Snedden, J.D., Sinclair, C.D. (1989). Statistical mapping and analysis of engineering ceramics data. In Mechanics of Creep Brittle Materials, Springer, Dordrecht, 1: 99116. https://doi.org/10.1007/978-94-009-1117-8_8

[26] Tool, A.Q. (1946). Relation between inelastic deformability and thermal expansion of glass in its annealing range. Journal of the American Ceramic Society, 29(9): 240-253. https://doi.org/10.1111/j.11512916.1946.tb11592.x

[27] Narayanaswamy, O. (1971). A model of structural relaxation in glass. Journal of the American Ceramic Society, 54(10): 491-498. 
https://doi.org/10.1111/j.1151-2916.1971.tb12186.x

[28] Bauer, F., Kempf, M., Weiland, F., Middendorf, P. (2018). Structure-property relationships of basalt fibers for high performance applications. Composites Part B: Engineering, 145: 121-128. https://doi.org/10.1016/j.compositesb.2018.03.028

[29] Zhu, L., Sun, B., Hu, H., Gu, B. (2010). Constitutive equations of basalt filament tows under quasi-static and high strain rate tension. Materials Science and Engineering: A, 527(13-14): 3245-3252. https://doi.org/10.1016/j.msea.2010.02.015

[30] Wu, D., Zhou, J., Li, Y. (2006). Unbiased estimation of Weibull parameters with the linear regression method. Journal of the European Ceramic Society, 26(7): 10991105. https://doi.org/10.1016/j.jeurceramsoc.2005.01.044

[31] Zinck, P., Pay, M.F., Rezakhanlou, R., Gerard, J.F. (1999). Mechanical characterisation of glass fibres as an indirect analysis of the effect of surface treatment. Journal of Materials Science, 34(9): 2121-2133. https://doi.org/10.1023/A:1004572112470

[32] Xing, D., Xi, X.Y., Ma, P.C. (2019). Factors governing the tensile strength of basalt fibre. Composites Part A: Applied Science and Manufacturing, 119: 127-133. https://doi.org/10.1016/j.compositesa.2019.01.027
[33] Makhova, M.F. (1968). Crystallization of basalt fibers. Glass and Ceramics, 25(11): 672-674. https://doi.org/10.1007/BF00674997

[34] Gutnikov, S.I., Manylov, M.S., Lipatov, Y.V., Lazoryak, B.I., Pokholok, K.V. (2013). Effect of the reduction treatment on the basalt continuous fiber crystallization properties. Journal of Non-Crystalline Solids, 368: 45-50. https://doi.org/10.1016/j.jnoncrysol.2013.03.007

\section{NOMENCLATURE}

$\begin{array}{ll}A_{n}^{2} & \text { Anderson-Darling statistics } \\ \mathrm{m} & \text { Weibull modulus } \\ \mathrm{n} & \text { Number of tested fibers } \\ \mathrm{P}_{\mathrm{f}} & \text { Probability of failure } \\ \mathrm{P}_{\mathrm{i}} & \begin{array}{l}\text { Probability of failure associated to the ith } \\ \text { ranked value of tensile strength }\end{array}\end{array}$

\section{Greek symbols}

$\theta \quad$ Angle of incidence, ${ }^{\circ}$

$\sigma \quad$ Tensile strength, $\mathrm{MPa}$

$\sigma_{0} \quad$ Scale parameter 